\title{
Free Tissue Transfer in Pediatric Lower Limb Trauma
}

\author{
R. Srikanth ${ }^{1}$ \\ ${ }^{1}$ Department of Plastic and Reconstructive Surgery, Nizams \\ Institute of Medical Sciences, Hyderabad, Telangana, India
}

\begin{abstract}
Address for correspondence Dr. R. Srikanth, MCh, Flat 303, Kakatiya Residency, Plot 183 Motinagar, Hyderabad-500 018, Telangana, India (e-mail: drsrikanthr@gmail.com).
\end{abstract}

Indian J Plast Surg 2019;52:37-44

\begin{abstract}
Keywords

- free flaps

- lower limb trauma

- pediatric

Free tissue transfer has become the standard in wound coverage and further refinements have given us newer flap donor sites or modifications of existing flaps to decrease morbidity; smaller vessels are being anastomosed, a direct spin-off following successful distal replantations. Younger children are presenting with traumatic defects similar to adults. Although there were apprehensions of free tissue transfer in children occasioned by smaller vessels, duration of procedure and concerns of growth following flap harvest, reports of small and large series have appeared in the literature with similar success. Pediatric-free tissue transfer is now an established entity. This article seeks to arrive at a consensus based on a review of the existing literature on free flaps for skin and soft-tissue coverage of lower limb trauma in children.
\end{abstract}

\section{Introduction}

It is pertinent to first agree, as to what group of patients constitutes a "pediatric" population before reviewing microsurgical tissue transfer in lower limb trauma.

The Indian Academy of pediatrics in its "Policy on age of children for pediatric care (1999)" states-"or fulfilling the professional obligations of pediatricians to the society at large, the purview of pediatrics commences with the fetus and continues through newborn, infancy, preschool and school age including adolescence up to and including 18 years of age."1

Be that as it may, more studies have used an upper age limit of 14 to 16 years, to define a study population as "pediatric."2,3 Meta-analysis studies, that have combed the literature for pediatric-free tissue transfer, have used 18 years as the upper age limit ${ }^{4}$; but the authors caution that future studies should exclude ages 16 years and above as they "no more have a pediatric tissue architecture."

In a 3-year retrospective study of 1148 cases at a tertiary center within the country, more than $50 \%$ of all injuries in children were consequent to road traffic accidents, but only approximately $10 \%$ of them involved the lower limb; such injuries were more likely to occur in the 6 to 15 years of age groups. ${ }^{5}$ School going children are more vulnerable to sustain lower limb injuries following road accidents, and these predominantly involve the ankle and foot rather than the leg. ${ }^{6}$

Since the first description of free groin flaps in children by Hari and Ohmori in 1975, free tissue transfers have been done for varying indications in the pediatric population.
Parry et al in 1988 reported on a large series of free flaps, of which 22 were in the lower limb, with a success of $96 \%{ }^{8}$

The earliest flap to be used in greater numbers was the latissimus dorsi flap. ${ }^{9,10}$ Subsequently, as in adults, other perforator-based flaps of skin have been used in children as they minimize donor site morbidity and permit tailoring of tissue needs at the recipient site..$^{2,11-13}$

The scope of this article is restricted to acute and nonacute traumatic lower limb wounds for the replacement of skin and soft tissue only.

The difference in free tissue transfer between children and adults, if any, can be analyzed using the following factors:

1. Location of defect

2. Size of vessels, vessel spasm, vascular evaluation

3. Choice of flap

4. Timing of reconstruction

5. Duration of surgery, the impact of general anesthesia

6. Re-exploration rates, anticoagulation

7. Failures, other complications

8. Secondary surgery.

\section{Location of Defect}

In a series of 22 patients below 18 years, 12 patients had Gustilo IIIB or IIIc injuries for which free flaps were done. ${ }^{14}$ On the contrary, a meta-analysis study revealed that the proportion of compound leg fractures needing a free flap is lower in the pediatric as against the adult population ( 75 vs. $90 \%){ }^{4}$ Of 21 free flaps following acute lower limb trauma, more published online April 16, 2019
DOI https://doi.org/

10.1055/s-0039-1688094 ISSN 0970-0358.
(C)2019 Association of Plastic Surgeons of India
License terms

(요 (1) $\odot$ 
than $90 \%$ were defects in the lower third of leg and the foot (-Figs. 1A-C and 2A, B and 3A, B). ${ }^{9}$

Most series of pediatric-free flaps for lower limb injuries have a higher quantum of foot and ankle injuries; this was $63 \%$ in the study by Serletti et al. ${ }^{15}$ Lin et al state that the energy of the trauma is diverted to the skin and soft tissues, causing exposure of foot tendons and the ankle joint; the long bones are less often damaged. In addition, the nonavailability of local tissues forces the choice of a free tissue transfer. ${ }^{2}$

\section{Vessel Size and Vessel Spasm}

Recipient vessels in children are likely to be small but do not preclude a safe microvascular anastomosis-even when the diameter is as less as $8 \mathrm{~mm} ; 21$ of 22 free flaps in a series of patients (which included replantations) with an average age of 5.4 years were uneventful. ${ }^{16}$

Where the vessels are smaller than $5 \mathrm{~mm}$, a thought should be given to perform multiple anastomosis as feasible, to increase flap success rates. ${ }^{4}$ Nine of 25 flaps needed two arterial anastomosis on account of small vessel size. ${ }^{9}$

Vessels size, when expressed as a ratio of the size of the patient, seems actually to be more than in adults ${ }^{12}$; it maybe the thinness rather than the vessel diameter that confers technical difficulty in pediatric-free flaps.

The routine practice of including body mass index, rather than the chronological age only, can make a comparison of microvascular success in pediatric-free flaps between different studies easier. ${ }^{17}$
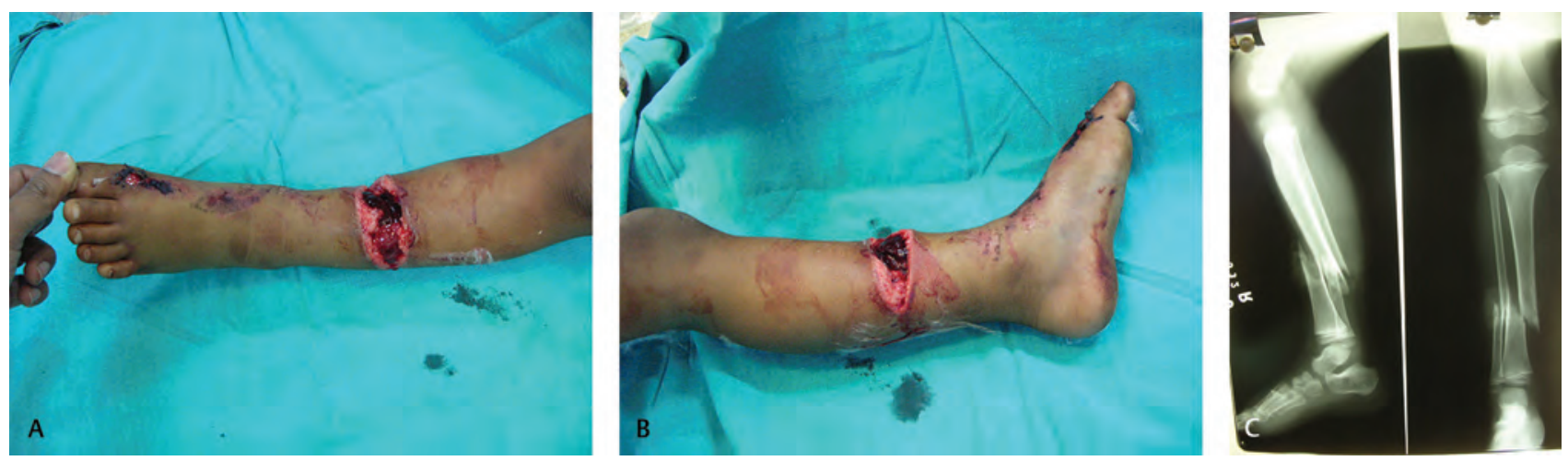

Fig. 1 (A) Clinical photo and X-ray of 5-year-old child with Gr Illb fracture middle third leg, (B) clinical photo and X-ray of 5-year-old child with Gr IIIb fracture middle third leg, (C) clinical photo and X-ray of 5 years child with Gr IIIb fracture middle third leg.
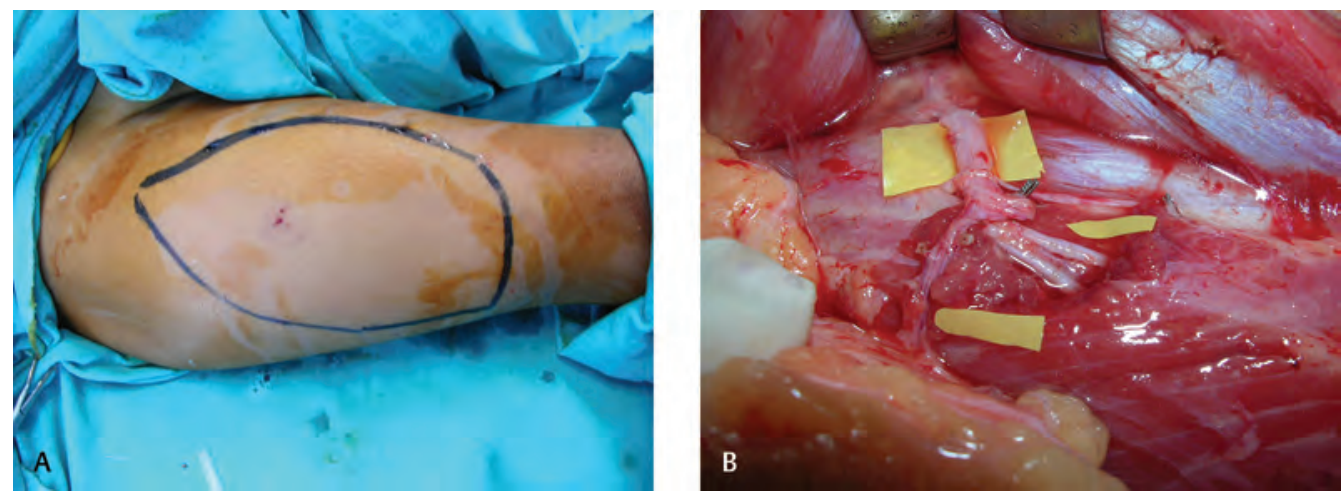

Fig. 2 (A) Proposed anterolateral thigh flap with septocutaneous perforator, and (B) proposed anterolateral thigh flap with septocutaneous perforator.
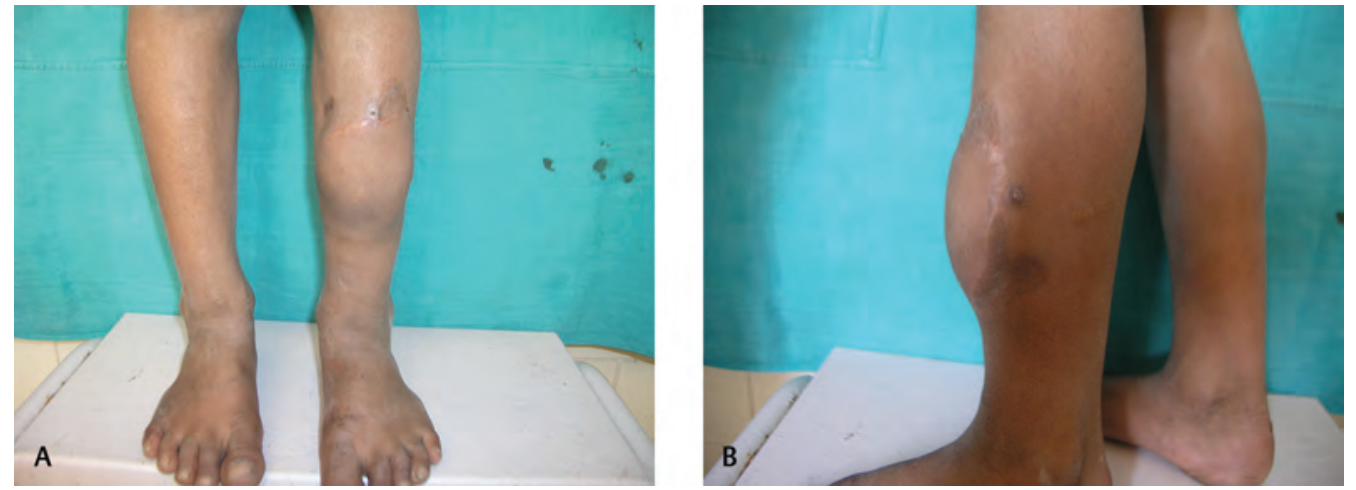

Fig. 3 (A) Follow-up after 6 months and without any debulking, and (B) follow-up after 6 months and without any debulking. 
Excessive vasospasm was hypothesized as a reason to approach pediatric-free tissue transfer with caution. Vessels in children are actually not more prone to spasm; authors have suggested that the immature vessel walls of children have a lesser component of muscle than in adult and thus could have a lower tendency to "spasm."8

If vascular spasm is not disproportionately high in children but similar as in the adult population, identical precipitating causes for flap failure are looked for: traumatic handling, a lower core body temperature or not "crossing the zone of trauma." Still, it is recommended that lesser adventitial dissection be done to prevent the onset of spasm and if spasm appears to use pharmacological adjuncts such as xylocaine and papaverine locally on the vessels wall. ${ }^{18}$

Duteille et al based on a study group of 22 patients with a mean age of 8.9 years recommend completion of vessel dissection under the microscope, both at the donor and recipient sites; the use of locoregional anesthesia for the involved lower limb further facilitates continued vasodilation to improve flap perfusion. ${ }^{11}$

Acar et al recommend that the anterolateral thigh (ALT) flap perforator be harvested with an obligatory "cuff of muscle" to increase the safety quotient. ${ }^{19}$

There are studies opining that the evaluation of vessels by angiography is not warranted except in the situation of a mangled limb which makes clinical examination difficult. ${ }^{11,16}$ Yücel et al advised Doppler examination of recipient vessels in all cases, and only 2 of 22 had an angiogram for severe gunshot injuries. ${ }^{20}$

For defects in the lower third leg and the foot, the anterior or posterior tibial is the vessel of choice for an end-to-end anastomosis; certain authors give preference to the posterior tibial, on account of a greater chance of injury to the anterior tibial vessels ${ }^{17} ; 20 \%$ of 40 patients had anastomosis to the posterior tibial vessels. This could also be on account of 11 cases of compound leg fractures of middle and lower third leg in their series-a greater proportion of all injuries than other authors who had more of ankle and foot trauma.

El-Gammal et al used the anterior tibial preferentially in 38 cases and posterior tibial artery only in four cases of foot and ankle injuries with more than $95 \%$ success rate. ${ }^{18}$ Hence, proper intraoperative evaluation of the vessels for evidence of trauma prevents choosing the injured vessels for the microanastomosis.

Serletti and Moran have shown the use of peroneal vessels as the recipient pedicle after excision of a segment of the fibula in situations where scar limits the use of the other two axial vessels of the leg ( $\mathbf{- F i g . 4 A - F ) .}{ }^{21}$

The accompanying vein or veins are used for the flap drainage as a rule; a few authors recommend adding the great saphenous vein for venous drainage; in 6 of 25 ALT flaps, anastomosis to the great saphenous vein as the second venous drainage was done. ${ }^{17,22}$ The practice of performing two venous anastomosis seems to be not standard; certainly, the latissimus dorsi and the rectus abdominis afford the scope of a single venous anastomosis, ${ }^{23}$ whereas with most ALT flaps 2 anastomosis could be done.

\section{Choice of Flap}

The first reports of free flaps in children used a free groin flap; the donor site of a groin flap is ideal as it is closed primarily; the average area of flap for coverage was 60 to $190 \mathrm{~cm}^{2}$. It has not found favor in recent publications on account of anatomical variations in the origin of the source artery and a short pedicle length which prevents "crossing" the zone of trauma in extensive lower limb injuries. ${ }^{24}$

The latissimus dorsi muscle with or without an overlying skin paddle has been the most frequently used free flap in
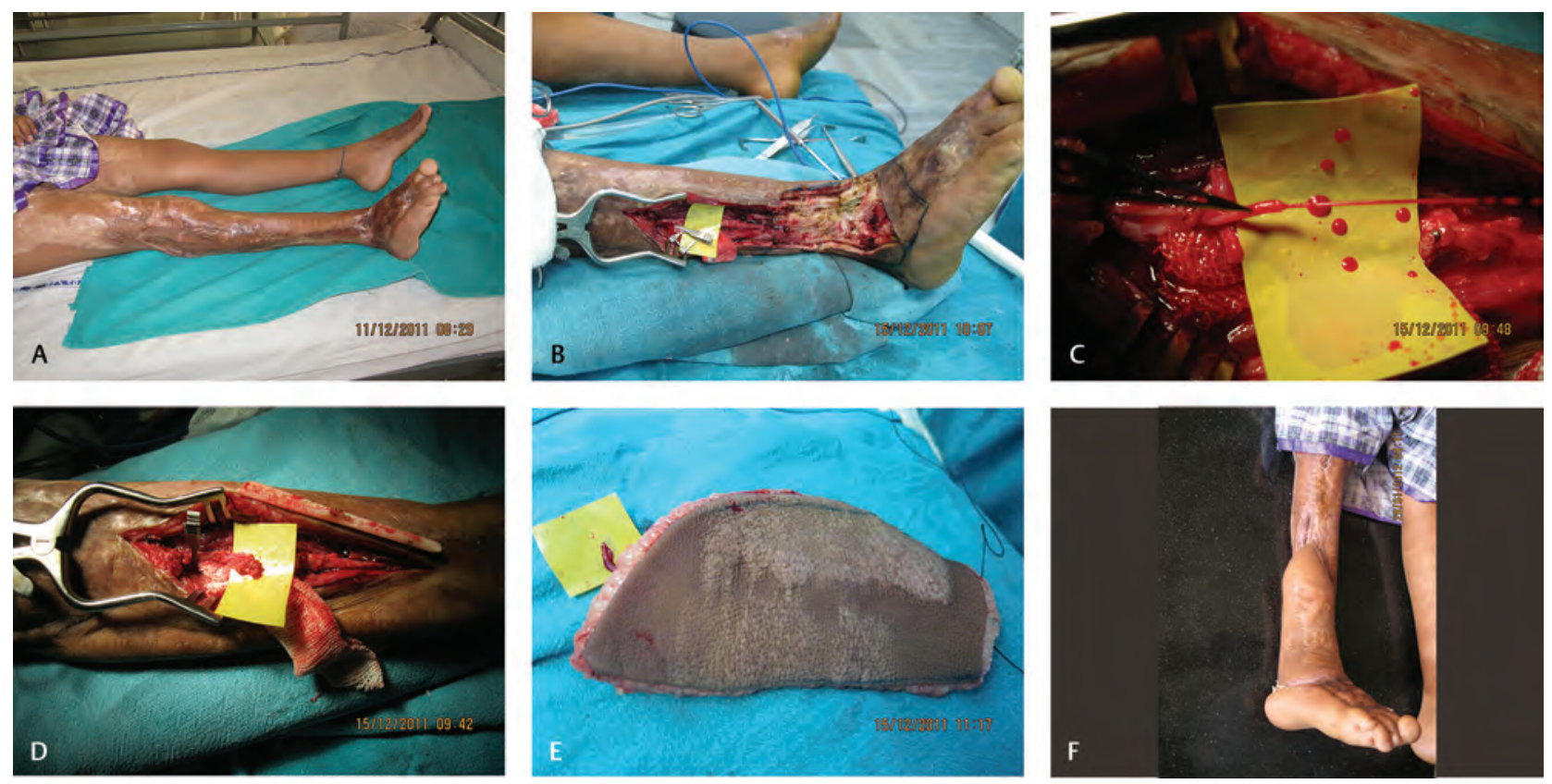

Fig. 4 (A) Post-traumatic deformity of right ankle 7-year-old child, (B) excision of a segment of the fibula for accessing the peroneal vascular pedicle, (C) demonstration of pulsatile flow, (D) excision defect with prepared recipient vessels, (E) anterolateral thigh flap harvested, and (F) follow-up photograph before planned ankle arthrodesis. 
the pediatric patients; 17 of 25 flaps in 23 patients with lower limb trauma had coverage with this flap. ${ }^{9}$ This is on account of a very constant pedicle of adequate length and enough surface area to cover large defects.

It has its drawbacks too-when used as a muscle only flap with a split skin graft the denervation of the muscle causes a predictable $100 \%$ atrophy and loss of volume; when taken as a myocutaneous flap for coverage of foot and ankle defects, the added bulk may not be suitable for the use of normal footwear; further, replacement of atrophied muscle by fibrous tissue can cause future appearance of scar contractures over the ankle and toes (Figs. 4A, B and 5A, B and 6A, B). ${ }^{4}$

The assumption of no morbidity following this muscle harvest may not entirely be true in the long term; authors have reported concern about shoulder function in the long term. Two patients below the age of 4 years had complaints of shoulder tightness, and one had rib fractures twice at 6-year follow-up. ${ }^{9}$ This observation has not been replicated anywhere else in the literature. They recommended the use of only a part of the muscle as described by other authors. ${ }^{25}$ This could restrict the application of this flap to only small and moderate defects. In addition, when only a segmental muscle flap is done, putting the patient in a true lateral position may not be necessary, affording the chance of a truly "two team approach."

There is actually no morbidity following gracilis muscle harvest, but the only disadvantage is a smaller vessel size; small defects over the ankle and foot can be covered by the gracilis flap. The spread of the muscle can be increased by careful removal of the epimysium to increase surface area by even $100 \%$, thus permitting coverage of moderate defects. ${ }^{26}$

The advent of the ALT flap nourished by musculocutaneous or septocutaneous perforators avoids the obligatory harvest of the underlying muscle; hence, both bulk at recipient site are avoided, and there is no donor morbidity as in a musculocutaneous flap. ${ }^{2,9,22}$ Large amounts of skin can be harvested on a single pedicle. A completely two team approach expedites the surgical reconstruction in the shortest possible time.
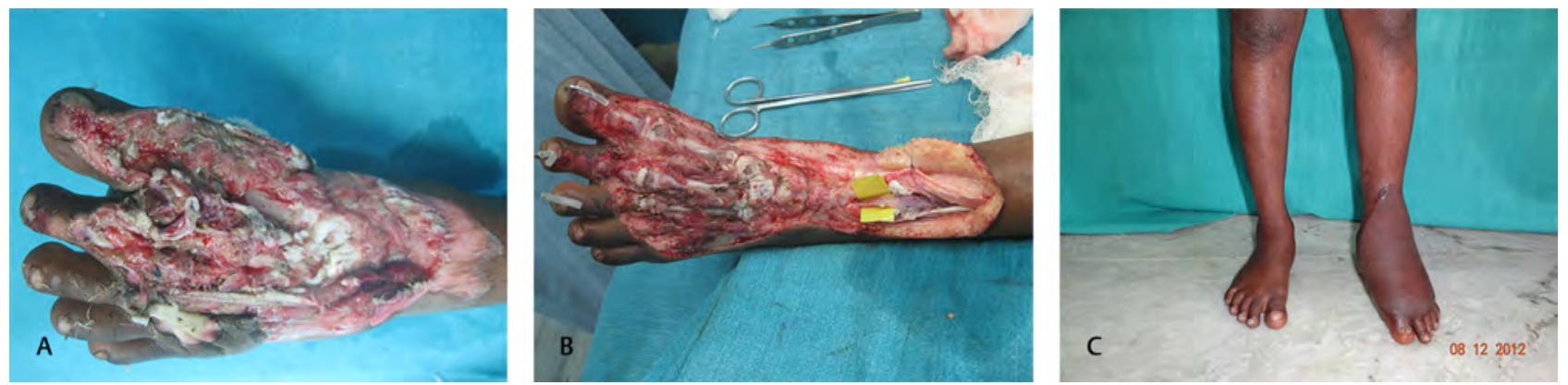

Fig. 5 (A) Crush injury dorsum foot with crushed tarsals and metatarsal fractures in a 3-year-old child, (B) debridement $\mathrm{K}$ wire fixation and anterior tibial vessels dissected, and (C) settled anterolateral thigh flap after 12 months before any thinning.
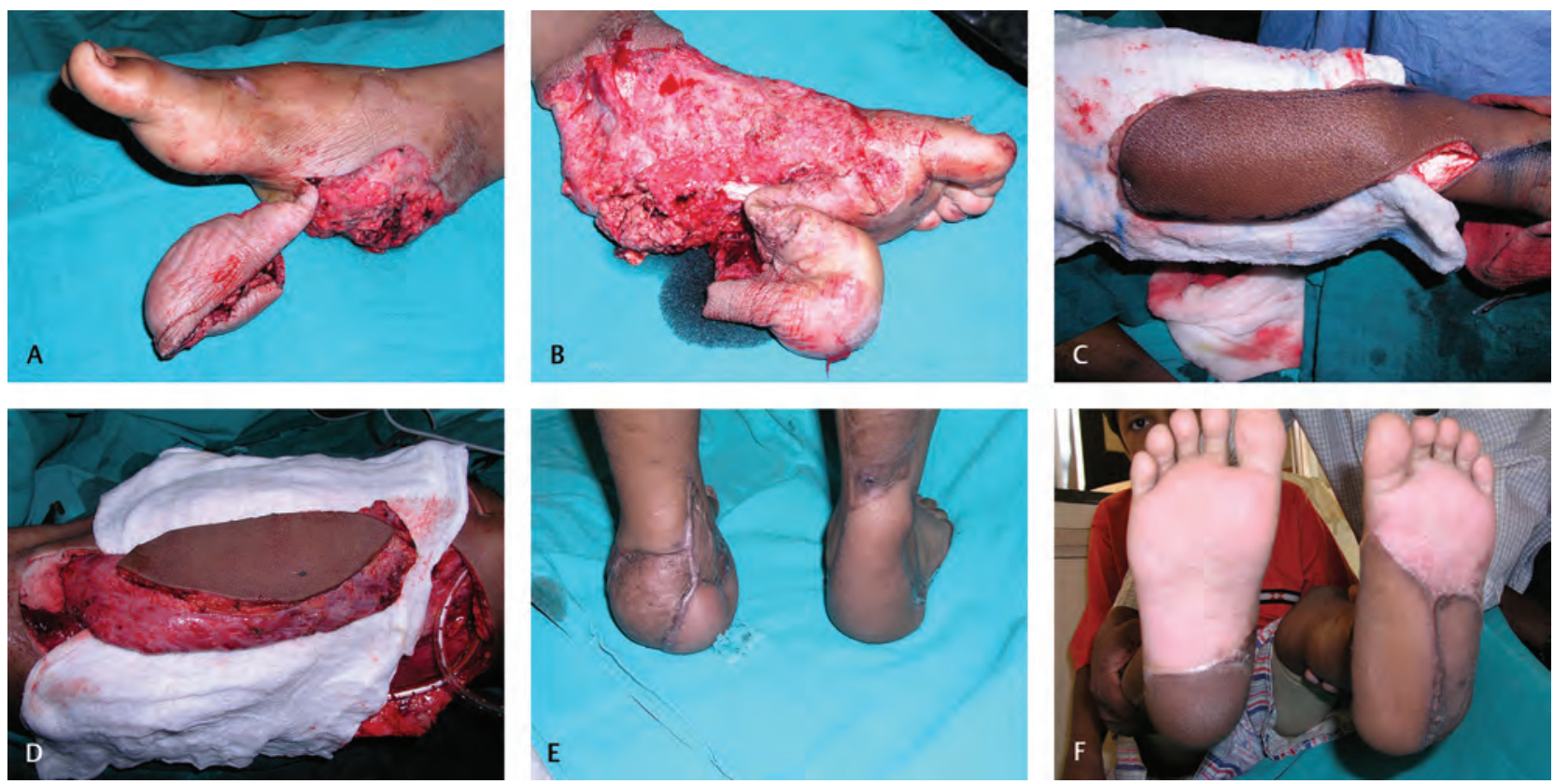

Fig. 6 (A) Avulsion injury of the right foot in a 9-year-old child, (B) avulsion injury of the left foot in same child, (C) distally based sural artery flap for the right foot, (D) latissimus dorsi myocutaneous flap for the left foot, (E) follow-up photos of feet after 2 years, and (F) follow-up photos of feet after 2 years. 
This flap also permits primary tendon reconstruction, especially in the foot and the ankle either by using free fascia lata grafts or a vascularized fascia lata bridge; 20 of 42 patients underwent primary tendon repair or grafting simultaneously with flap transfer successfully² $\mathrm{Hu}$ et al used free fascial grafts (iliotibial band) for tendon repair in a series of 25 patients ( - Fig. 5A-C). ${ }^{22}$

The other flaps that have been used in smaller series are the rectus abdominis, ${ }^{23}$ scapular and parascapular flaps, ${ }^{11}$ the thoracodorsal artery perforator type flaps, ${ }^{27}$ deep inferior epigastric perforator (DIEP) flap, ${ }^{12}$ and the radial artery forearm flap. ${ }^{15}$

\section{Timing}

Highest free flap success rates have been correlated to intervention within 72 hours of trauma with failures increasing during the evolution of the subacute stage from 72 hours to 6 weeks. ${ }^{28}$ Rinker et al had statistically significant increase in flap complications in a group of 12 children undergoing free flaps before and after 7 days. ${ }^{14}$

Karanas et al in a series of 14 free flaps, with an average time of surgery at 22 days had no flap $\operatorname{loss}^{29}$; the authors used negative pressure wound therapy (NPWT) following serial debridements before flap cover. In a meta-analysis study, Christopoulos identified 83 patients who had a delayed, and only 7 had immediate flap cover with a $<5 \%$ partial or total flap loss. ${ }^{30}$

The lead time to flap cover was a mean of 15.8 days after trauma. ${ }^{18}$ Meantime to coverage of 25 patients undergoing free ALT flaps for the foot was 8.7 days. ${ }^{24}$ These authors and others use NPWT after the initial debridement to resolve tissue edema and prevent desiccation. Six of 10 patients undergoing free flap for compound leg fractures had NPWT before surgery. ${ }^{31}$

\section{Duration of Surgery and Impact of General Anesthesia}

There is an unsaid implication that free flaps in children may take more time than in adults. Parry et al showed an average operative time of 7.9 hours in children with a mean age mean age of 9 years from 16 months to 15 years $^{8}$; other studies have shown it to be comparable in children and adults -5.9 hours as against 6.4 hours in the adult ages. ${ }^{9}$ El-Gammal reported an average of 6.33 hours using ALT flaps for foot and ankle defects. ${ }^{18}$ Certainly, flaps which can be elevated in a two-team approach, like the ALT, DIEP, in fact, any flap that is not based on the thoracodorsal-subscapular axis further telescopes the duration of surgery.

Children tolerate anesthesia better than adults with a shorter hospital stay; peripheral nerve blockade with or without indwelling catheters can decrease postoperative pain and also decrease sympathetic tone to favorably perfuse the free flap. ${ }^{32}$

Doing the entire surgery under regional anesthesia in older children has been described; 20 patients with a mean age of 12.1 years operated under regional anesthesia for the lower limb with a range of 3 to 4 hours for ALT and gracilis flaps and the authors cite earlier recovery, better postoperative pain relief. ${ }^{33}$

There is a risk of hypothermia if the duration of surgery is prolonged; this has been found to have adverse effects leading to increased incidence of skin and soft-tissue infections, increased bleeding due to dilution of procoagulants in the blood, and alteration of blood levels of anesthetic drugs. ${ }^{34} \mathrm{~A}$ conscious effort needs to be made as regards maintaining ambient temperature, the use of warmed normal saline irrigation solutions locally and replacement of soaked operative towels and drapes.

Namdar et al had one case of flap failure directly traced to intraoperative hypervolemia causing hemodilution-induced vascular thrombosis, thus underscoring the importance of adequate and proper intravenous fluid management in children. ${ }^{10}$

Table 1 Rates of re-exploration and salvage in select studies

\begin{tabular}{|l|l|l|l|l|l|}
\hline Year & Authors & Numbers & Re-Exploration & Salvage & Reference \\
\hline 1997 & Chiang et al & 23 & $12 \%$ & $66 \%$ & 9 \\
\hline 2006 & Lin et al & 91 & $10.75 \%$ & $60 \%$ & 2 \\
\hline 2013 & El-Gammal et al & 42 & $7.14 \%$ & $66 \%$ & 18 \\
\hline 2015 & Acar et al & 11 & $9.1 \%$ & $100 \%$ & 19 \\
\hline 2013 & Aboelatta and Aly & 28 & $10.7 \%$ & $100 \%$ & 23 \\
\hline 2018 & Christopoulos & 102 & $5.89 \%$ & $66 \%$ & 30 \\
\hline
\end{tabular}

Table 2 Practice of anticoagulation in select studies

\begin{tabular}{|l|l|l|l|l|l|l|}
\hline & Numbers & $\begin{array}{l}\text { Mean } \\
\text { age }\end{array}$ & Criteria & Peroperative & Postoperative & Ref \\
\hline Canales et al 1991 & $106^{\mathrm{a}}$ & 9 & All patients & Dextran $3 \mathrm{~d}$ & Aspirin 4 wks & 3 \\
\hline Chiang et al 1997 & 21 & 7.1 & Trauma, small vessels & Dextran $3 \mathrm{~d}$ & Aspirin $4 \mathrm{wks}$ & 9 \\
\hline El-Gammal et al 2012 & 42 & 6.18 & All patients & Dextran $10 \mathrm{~mL} / \mathrm{kg} / 24$ hour for $5 \mathrm{~d}$ & - & 18 \\
\hline Acar et al 2015 & 11 & 8.9 & All patients & $30 \mathrm{IU} / \mathrm{kg}$ before clamp application & - & 19 \\
\hline Hu et al 2015 & 25 & 8.32 & All patients & Dextran $10 \mathrm{~mL} / \mathrm{kg} / 24 \mathrm{~h}$ for $5 \mathrm{~d}$ & - & 22 \\
\hline
\end{tabular}

aMixed indications including lower limb. 


\section{Re-Exploration Rates, Failures}

Re-exploration rates in children, as against adults, were 17 and 13\%, respectively, in a mixed group of 106 patients (of which $\sim 34 \%$ were for the lower limb). ${ }^{3}$ The authors further opined that the salvage rates in children were less than in the adults, but no statistical interpretation was obtained-43 against 55\%, respectively. A chronological table of re-exploration rates and salvage percentage in lower limb trauma for authors with more than 10 cases is shown in -Table $\mathbf{1}$.

Hence, the re-exploration rates are comparable to adult studies with an average two of three re-explored flaps being salvaged.

Flap failure rates in children are also comparable to adults and range from 2 to $12 \% .^{2,3}$

A meta-analysis study concluded that the flap failure rates in children are $5.01 \%$ as against $3.7 \%$ in adults. ${ }^{4}$ A $21 \%$ failure rate was observed in one study of 14 patients; the authors stated that the frequency of such reconstructions in their unit was low: 1 per year. ${ }^{10}$ Christopoulos identified a $4.9 \%$ rate in 102 patients undergoing ALT flaps for foot and ankle injuries. ${ }^{30}$

The failure rate in another series of 21 cases operated with a mean age of 5 years was $0 \%$; there was only one re-exploration successfully salvaged; the rectus abdominis muscle was the only flap used. ${ }^{23}$

Choosing a flap that the surgeon is most comfortable with, or using the minimum variety of flaps for different indications negates the chances of "learning curve" induced flap failure.

\section{Anticoagulation, Other Complications}

The use of anticoagulation or blood flow modifying drugs seems to be empirical. - Table 2 lists their use by authors with a series of more than 10 cases of lower limb trauma. Other authors have agreed that heparin would be used intraoperatively only if there were a blocked anastomosis or smaller vessel size; postoperatively, this would be continued for 3 to 7 days., $4,16,23$

The other complications during hospital stay include wound dehiscence, infection, donor site hematomas, and split skin graft loss. Donor site hematomas were twice as common in children as in adults with similar donor sites probably on account of the difficulty of restraining children. ${ }^{2}$ Arslan et al had 33.3\% minor complications of a nonvascular nature for 10 cases with leg and foot injuries. ${ }^{31}$

Christopoulos documented 22\% complications in 102 ALT flaps for the foot, and other authors have had rates between 17.5 and 32\%2,17,30 These nonanastomotic complication rates can be kept down by meticulous postoperative care that is not related to patient age.

A systematic review by Claes and Van Landuyt et al compiling data about various donor sites in pediatric-free tissue transfer concludes the following figures. ${ }^{24}$ These data did not make a distinction between vascular and nonvascular complications but certain inferences could be made:

- $<15 \%-$ ALT flap

- 15 to 30\%-rectus abdominis, gracilis, and groin flaps

- >30\%-flaps based on the thoracodorsal subscapular axis

\section{Explanations:}

1. The higher complications with the thoracodorsal axis flaps were on account of more donor complications and distal necrosis of the scapular flap as well as partial necrosis of the latissimus muscle flaps.

2. Smaller numbers of groin flaps with $20 \%$ partial necrosis could be due to learning curve; rectus abdominis had no vascular complications but donor morbidity

3. Truly low complications were observed in 71 patients with only one total and three partial necrosis when the ALT flap was used.

A large study of 226 flaps local and free in all foot injuries of which there were 20 patients in the pediatric group recommends the use of a free ALT flap if more than 1 subunit of the foot needed coverage; the use of a free latissimus dorsi flap with or without skin paddle is restricted to their use in infected and cavitary wounds only. ${ }^{35}$

\section{Secondary Procedures}

The most detailed long-term sequelae following free flaps are by Lin et al. ${ }^{2}$

About $45.9 \%$ patients develop long-term complications: dorsal flexion contractures, plantar flexion contractures, valgus deformities, and equinovarus deformities.

Secondary deformities such as bulk and contracture are more with skin grafted free muscle flaps rather than skin flaps $^{2}$; the results were statistically significant; 58.9 versus $37.9 \%$ for all foot and ankle cases.

A significant number of patients who undergo free flaps for the weight-bearing regions of the foot, be they muscle flaps or skin flaps, need secondary procedures such as ulcer excision and transfer of local or free sensate skin flaps secondarily. ${ }^{2}$ Other authors have documented a 25 to $30 \%$ need for secondary surgery. ${ }^{17,30}$ An empirical observation has been that since children are more pliable to learn new gait patterns to offload insensate areas of the foot, they fare better than adults with a similar reconstruction (-Fig. 6A-F).

\section{Author's Experience}

Over a 15-year period, 100 consecutive free flaps in the pediatric age group (defined as $<14$ years of age) were analyzed. Seventy-seven of these were following acute trauma and 23 for post-traumatic defects. About 66\% of all defects were located in the foot, 15\% at the ankle and 19\% for compound leg fractures. Fifty-two latissimus dorsi and 48 ALT flaps were used; only 3 of 52 muscle flaps were used in post-traumatic defects. In the acute injuries, 49 muscle flaps and 28 ALT flaps were used. All patients received only low molecular weight dextran as a continuous infusion for 3 days.

Twelve of these flaps needed re-exploration, of which six could be salvaged (50\%). In addition, two flaps were lost after the eighth postoperative day after being viable in the early postoperative period.

Among the six cases of early flap loss, four cases were due to venous thrombosis consequent to the "zone of trauma"; 
two were arterial: post-traumatic vessel disease leading to arterial failure in the only elective flap loss, and a poorly chosen recipient artery in the presence of an abnormal anterior tibial artery in one, leading to arterial thrombosis.

The two flaps that were lost late were hypothesized to be a combination of cold exposure and dehydration, as there was no evidence of any compression or infection during removal of the necrosed flap.

Three of the four cases where the zone of trauma was implicated were total or subtotal degloving injuries of the foot; the other was a compound leg fracture of the upper third of the leg.

Except the one case of upper third fracture, where a cross leg flap was used after flap loss, the other six wounds healed only with secondary skin grafting. Only one of the six cases of flap loss at the foot needed distal metatarsal amputation following flap failure.

\section{Summary}

We can summarize the topic as follows:

1. Injuries of the distal third of leg and foot in children afford opportunities for the increasing use of free flaps for skin and soft-tissue coverage.

2. It is the debridement that is the emergency; this needs to be expedited at the earliest and definitive wound coverage can be deferred for a suitable future time with no compromise in free flap success. In the interim, NPWT provides a closed wound preventing infection and resolving edema. Certainly, this protocol should be followed if there are other injuries, multiple injuries, or systemic factors that can compromise the health of the patient if the entire reconstruction was done in a single stage.

3. The size of the vessels is not the deciding factor to dictate success or failure; rather an anastomosis, staying well away from the zone of trauma and adherence to other principles of microsurgery, no different from adults, increases flap success. The rules of treating vascular spasm are the same as in the adult, and it is no more believed that vessels in children are more vulnerable to spasm.

4. In most open injuries, clinical evaluation and intraoperative assessment of flow can help in choosing the proper vessels for anastomosis. In mangled limbs awaiting salvage and where the additional closed proximal vascular injury is suspected, there may be a role for peripheral angiography. The use of a hand-held Doppler in the thigh for perforator evaluation before ALT flap harvest is similar as in adults.

5. Since the venous system is a low-pressure system, wherever feasible it should be the practice to anastomose two veins instead of one.

6. The choice of flap, although numerous, needs to be protocolized to individual or unit experience for their differing locations along the "learning curve." For small defects, the gracilis, the lateral arm, or any of the newer perforator-based flaps can be used; the larger defects need a latissimus dorsi muscle or the ALT.
7. Although tendon reconstruction can be done under a well-done muscle flap, a skin flap is preferred in these situations especially over the dorsum of the foot.

8. Skin flaps offer predictable bulk and contour that can be reduced in further surgeries, whereas the long-term behavior of muscle flaps with respect to contour or bulk is less predictable.

9. Problems at the donor site are less tolerated when flaps like scapular, radial forearm, or rectus abdominis flaps are chosen.

10. When free flaps are done for the weight-bearing areas of the foot, long-term sequelae result regardless of whether it is a skin grafted muscle, only skin or innervated skin flap. When a large defect has been closed with a muscle or skin flap, future innervated flap transfers, local or free, to provide sensation in critical areas of ulceration or instability should be anticipated.

11. Since children have a smaller body surface area and a greater elastic recoil of the skin, with increased shrinkage of skin flaps after harvest, a thought should be given in mentally picturing a large defect into critical and noncritical components; this would decrease flap requirements without compromising coverage issues.

12. A well-planned procedure does not prolong the duration of surgery and adopting a two-team approach lessens the time; regional blocks for postoperative pain relief and usage of epidural and spinal anesthesia for the entire procedure in older children are possible.

13. Management in an intensive care unit or high dependency unit setting permits monitoring, good fluid management, and ambient temperature control, the lack of which may delay re-exploration or even cause delayed flap necrosis (as children and the very elderly are more susceptible to changes in hydration and temperature changes).

14. Re-exploration rates of 8 to $15 \%$ can be predicted with salvage rates of 40 to $60 \%$.

15. Flap loss rates below $5 \%$ should be the aim keeping in mind that the healing and tissue regeneration potential of children is far better than adults as evinced by the fact that after free flap failure in the foot, a combination of NPWT and dressings can produce a graftable wound to permit wound closure in the short term.

16. Flap harvest usually has no implications for future growth and donor morbidity is the result of perioperative or immediate postoperative events only.

17. Transferred flaps grow with the patient but it may either not be exactly commensurate or the scars (which are less than optimal in the young) may have restrictive effects that manifest later as contractures in the foot and ankle.

\section{Conclusion}

Free tissue transfer in pediatric lower limb trauma is an extension of the same principles as in adults. A greater care and adherence to technique are needed considering the smaller physique. Using a minimum repertory of flaps for defects small 
and large will ensure the maximum cost-benefit ratio for the individual clinical case. Improving results in free flaps for lower limb trauma, where most patients are in the school age group, is an encouragement to step into "truly pediatric" free flaps for congenital conditions in the preschool children.

\section{Conflicts of Interest}

There are no conflicts of interest.

\section{References}

1 Available from https://www.indianpediatrics.net/may1999/ may-461-463.htm. Accessed August 9, 2018

2 Lin CH, Mardini S, Wei FC, Lin YT, Chen CT. Free flap reconstruction of foot and ankle defects in pediatric patients: long-term outcome in 91 cases. Plast Reconstr Surg 2006;117(7):2478-2487

3 Canales F, Lineaweaver WC, Furnas H, et al. Microvascular tissue transfer in paediatric patients: analysis of 106 cases. Br J Plast Surg 1991;44(6):423-427

4 Jabir S, Sheikh F, Fitzgerald O'Connor E, Griffiths M, Niranjan N. A systematic review of the applications of free tissue transfer for paediatric lower limb salvage following trauma. J Plast Surg Hand Surg 2015;49(5):251-259

5 Kundal VK, Debnath PR, Sen A. Epidemiology of pediatric trauma and its pattern in urban India: a tertiary care hospital-based experience. J Indian Assoc Pediatr Surg 2017;22(1):33-37

6 Elbaiah AH, Taha M, Saker A, Aziz S, Shahate A. Patterns of extremities trauma in children and their management in emergency department in Suez Canal University hospital Ismailia Egypt. Int Surg J 2016;3:887-892

7 Harii K, Ohmori K. Free groin flaps in children. Plast Reconstr Surg 1975;55(5):588-592

8 Parry SW, Toth BA, Elliott LF. Microvascular free-tissue transfer in children. Plast Reconstr Surg 1988;81(6):838-840

9 Chiang YC, Jeng SF, Yeh MC, Liu YT, Chen HT, Wei FC. Free tissue transfer for leg reconstruction in children. Br J Plast Surg 1997;50(5):335-342

10 Namdar T, Stollwerck PL, Stang FH, Lange T, Mailänder P, Siemers F. Latissimus dorsi muscle flap for lower extremity reconstruction in children. Microsurgery 2010;30(7):537-540

11 Duteille F, Lim A, Dautel G. Free flap coverage of upper and lower limb tissue defects in children: a series of 22 patients. Ann Plast Surg 2003;50(4):344-349

12 Van Landuyt K, Hamdi M, Blondeel P, Tonnard P, Verpaele A, Monstrey S. Free perforator flaps in children. Plast Reconstr Surg 2005;116(1):159-169

13 Ozkan O, Ozkan O, Cinpolat A, Bektas G. Reconstruction of distal lower extremities defect using the free peroneal artery perforator vessel based flap. Microsurgery 2014;34(8):629-632

14 Rinker B, Valerio IL, Stewart DH, Pu LL, Vasconez HC. Microvascular free flap reconstruction in pediatric lower extremity trauma: a 10-year review. Plast Reconstr Surg 2005;115(6):1618-1624

15 Serletti JM, Schingo VA Jr, Deuber MA, Carras AJ, Herrera HR, Reale VF. Free tissue transfer in pediatric patients. Ann Plast Surg 1996;36(6):561-568

16 Devaraj VS, Kay SP, Batchelor AG, Yates A. Microvascular surgery in children. Br J Plast Surg 1991;44(4):276-280
17 Momeni A, Lanni M, Levin LS, Kovach SJ. Microsurgical reconstruction of traumatic lower extremity defects in the pediatric population. Plast Reconstr Surg 2017;139(4):998-1004

18 El-Gammal TA, El-Sayed A, Kotb MM, et al. Dorsal foot resurfacing using free anterolateral thigh (ALT) flap in children. Microsurgery 2013;33(4):259-264

19 Acar MA, Güleç A, Aydin BK, Erkoçak ÖF, Yilmaz G, Senaran H. Reconstruction of foot and ankle defects with a free anterolateral thigh flap in pediatric patients. J Reconstr Microsurg 2015;31(3):225-232

20 Yücel A, Aydin Y, Yazar S, Altintaş F, Senyuva C. Elective free-tissue transfer in pediatric patients. J Reconstr Microsurg 2001;17(1):27-36

21 Serletti JM, Moran SL. Soft tissue coverage options for dorsal foot wounds. Foot Ankle Clin 2001;6(4):839-851

22 Hu R, Ren YJ, Yan L, et al. A free anterolateral thigh flap and iliotibial band for reconstruction of soft tissue defects at children's feet and ankles. Injury 2015;46(10):2019-2023

23 Aboelatta YA, Aly HM. Free tissue transfer and replantation in pediatric patients: technical feasibility and outcome in a series of 28 patients. J Hand Microsurg 2013;5(2):74-80

24 Claes K, Van Landuyt K. A Systematic Review: Free Flaps for Lower Limb Reconstruction in Children. Available from; https://www.lib.ugent.be/fulltxt/RUG01/002/350/465/ RUG01-002350465_2017_0001_AC.pdf

25 Elliott LF, Raffel B, Wade J. Segmental latissimus dorsi free flap: clinical applications. Ann Plast Surg 1989;23(3):231-238

26 Holle J, Worseg A, Kuzbari R, Würinger E, Alt A. The extended gracilis muscle flap for reconstruction of the lower leg. $\mathrm{Br} \mathrm{J}$ Plast Surg 1995;48(6):353-359

27 Lee SH, Mun GH. Transverse thoracodorsal artery perforator flaps: experience with 31 free flaps. J Plast Reconstr Aesthet Surg 2008;61(4):372-379

28 Godina M. Early microsurgical reconstruction of complex trauma of the extremities. Plast Reconstr Surg 1986;78(3): 285-292

29 Karanas YL, Nigriny J, Chang J. The timing of microsurgical reconstruction in lower extremity trauma. Microsurgery 2008;28(8):632-634

30 Christopoulos G. The free anterolateral thigh flap for microsurgical reconstruction of traumatic defects in paediatric foot: a systematic review of international literature. J Surg Anaesth 2018;2:1-7

31 Arslan H, Çinar C, Bingöl UA, Yücel OA. Subacute and delayed period microsurgical management of traumatic extremity injuries in pediatric population. Microsurgery 2012;32(7):527-532

32 Inberg P, Kassila M, Vilkki S, Tarkkila P, Neuvonen P. Anaesthesia for microvascular surgery in children. A combination of general anaesthesia and axillary plexus block. Acta Anaesthesiol Scand 1995;39(4):518-522

33 Bjorklund KA, VenkatramaniH,Venkateshwaran G, BoopathiV, Raja Sabapathy S. Regional anesthesia alone for pediatric free flaps. J Plast Reconstr Aesthet Surg 2015;68(5):705-708

34 Hart SR, Bordes B, Hart J, Corsino D, Harmon D. Unintended perioperative hypothermia. Ochsner J 2011;11(3):259-270

35 Zhu YL, Wang Y, He XQ, Zhu M, Li FB, Xu YQ. Foot and ankle reconstruction: an experience on the use of 14 different flaps in 226 cases. Microsurgery 2013;33(8):600-604 